\title{
A Risk Prediction Model for Operative Mortality after Heart Valve Surgery in a Korean Cohort
}

\author{
Ho Jin Kim, M.D. ', Joon Bum Kim, M.D., Ph.D. ', Seon-Ok Kim, M.Sc. ${ }^{2}$, Sung-Cheol Yun, Ph.D. ${ }^{2}$, Sak Lee, M.D., Ph.D. ${ }^{3}$, \\ Cheong Lim, M.D., Ph.D. ${ }^{4}$ Jae Woong Choi, M.D. ${ }^{5}$, Ho Young Hwang, M.D., Ph.D. ${ }^{5}$ Kyung Hwan Kim, M.D. ${ }^{5}$, \\ Seung Hyun Lee, M.D., Ph.D. ${ }^{3}$, Jae Suk Yoo, M.D., Ph.D. ${ }^{6}$, Kiick Sung, M.D., Ph.D. ${ }^{7}$, Hyung Gon Je, M.D., Ph.D. ${ }^{8}$, \\ Soon Chang Hong, M.D., Ph.D. ${ }^{9}$ Yun Jung Kim, R.N., Ph.D. ${ }^{10}$, Sung-Hyun Kim, M.S. ${ }^{10}$, Byung-Chul Chang, M.D, Ph.D., \\ F.A.H.A. ${ }^{11}$ \\ Departments of ${ }^{1}$ Thoracic and Cardiovascular Surgery and ${ }^{2}$ Clinical Epidemiology and Biostatistics, Asan Medical Center, University of Ulsan College of \\ Medicine; ${ }^{3}$ Department of Thoracic and Cardiovascular Surgery, Severance Hospital, Yonsei University College of Medicine, Seoul; ${ }^{4}$ Department of Thoracic and \\ Cardiovascular Surgery, Seoul National University Bundang Hospital, Seoul National University College of Medicine, Seongnam; ${ }^{5}$ Department of Thoracic and \\ Cardiovascular Surgery, Seoul National University Hospital, Seoul National University College of Medicine, Seoul; ${ }^{6}$ Department of Cardiovascular Surgery, Sejong \\ General Hospital, Bucheon; 'Department of Thoracic and Cardiovascular Surgery, Samsung Medical Center, Sungkyunkwan University School of Medicine, \\ Seoul; ${ }^{8}$ Department of Thoracic and Cardiovascular Surgery, Pusan National University Yangsan Hospital, Yangsan; ${ }^{9}$ Department of Thoracic and Cardiovascular \\ Surgery, Wonju Severance Christian Hospital, Wonju; ${ }^{10}$ National Evidence-based Healthcare Collaborating Agency, Seoul; ${ }^{11}$ Department of Thoracic and \\ Cardiovascular Surgery, CHA Bundang Medical Center, CHA University School of Medicine, Seongnam, Korea
}

\section{ARTICLE INFO}

Received July 28, 2020

Revised September 7, 2020

Accepted September 9, 2020

\section{Corresponding author}

Byung-Chul Chang

Tel 82-31-780-5850

Fax 82-31-780-5857

E-mail bcchang@cha.ac.kr

ORCID

https://orcid.org/0000-0001-5005-8217

\begin{abstract}
Background: This study aimed to develop a new risk prediction model for operative mortality in a Korean cohort undergoing heart valve surgery using the Korea Heart Valve Surgery Registry (KHVSR) database.

Methods: We analyzed data from 4,742 patients registered in the KHVSR who underwent heart valve surgery at 9 institutions between 2017 and 2018. A risk prediction model was developed for operative mortality, defined as death within 30 days after surgery or during the same hospitalization. A statistical model was generated with a scoring system by multiple logistic regression analyses. The performance of the model was evaluated by its discrimination and calibration abilities.

Results: Operative mortality occurred in 142 patients. The final regression models identified 13 risk variables. The risk prediction model showed good discrimination, with a c-statistic of 0.805 and calibration with Hosmer-Lemeshow goodness-of-fit p-value of 0.630 . The risk scores ranged from -1 to 15, and were associated with an increase in predicted mortality. The predicted mortality across the risk scores ranged from $0.3 \%$ to $80.6 \%$.

Conclusion: This risk prediction model using a scoring system specific to heart valve surgery was developed from the KHVSR database. The risk prediction model showed that operative mortality could be predicted well in a Korean cohort.
\end{abstract}

Keywords: Risk prediction model, Mortality, Heart valve surgery

\section{Introduction}

Cardiovascular disease is the second most common cause of death in Korea [1], and valvular heart disease has been reported to affect approximately $9 \%$ of the Korean population [2]. Despite the recent rapid adoption of alternate transcatheter valve therapy [3,4], the number of heart valve operations has gradually increased owing to the growth of the aging population [5]. Approximately 14,000 cardiac surgical procedures are performed annually, and heart valve surgery has outpaced coronary artery bypass grafting (CABG) to become the most common cardiac procedure performed in Korea [6].

Risk assessment is an essential part of preoperative planning, both for cardiac surgeons and for patients and their families, and may contribute to the improved safety and quality of cardiac surgery. As such, 2 risk prediction models have been developed in the United States and Europe 
based on the nationwide or international cardiac surgery databases $[7,8]$. Although these risk prediction models have been widely adopted among global cardiac surgery communities, it has been suggested that a nation-specific risk prediction model that is developed based on a unique national database may predict the risk of surgery more adequately than the US or European models $[9,10]$.

The Korea Heart Valve Surgery Registry (KHVSR) was established as an official heart valve surgery database initiative of the Korean Society of Thoracic and Cardiovascular Surgery in 2017. Using this database, we developed the first risk prediction model for operative mortality in patients who undergo heart valve surgery in Korea.

\section{Methods}

\section{Study cohort}

The clinical and operative data of patients who underwent heart valve surgery at the 13 participating institutions in Korea have been prospectively registered in the KHVSR since January 2017. From the KHVSR database, we identified patients who received valve replacement/repair surgery with or without concomitant procedures between January 1, 2017 and December 31, 2018 from 9 of the 13 institutions that agreed to provide institutional data to develop the risk prediction model. This study was approved by the Institutional Review Board and Ethics Committee of each participating institution and the National Evidence-based Healthcare Collaborating Agency (IRB approval no., 19018-01). Informed consent was obtained from the patients who agreed to provide their clinical data to be registered in the KHVSR database.

\section{Data collection}

The KHVSR database contains information on each patient's preoperative risk profiles, laboratory and echocardiographic data, intraoperative details, and postoperative mortality and complications. Data were prospectively collected by a data manager or an operating surgeon at each participating institution using a dedicated electronic case report form (available online at http://heartvalve.or.kr). All patients who underwent heart valve surgery between January 1, 2017 and December 31, 2018 at the 9 institutions were registered in the KHVSR.

After the collection of data, all data were verified and queried for missing values or outliers by the first author (H.J.K.). The authors at each participating institution were responsible for the completion of data collection: data were validated by the authors at each institution, and an external audit was also performed on-site to evaluate the consistency and accuracy of the data.

\section{Statistical analyses}

SAS software ver. 9.4 (SAS Institute Inc., Cary, NC, USA) and R software ver. 3.6.1 (R Foundation for Statistical Computing, Vienna, Austria; http://www.r-project.org/) were used for the statistical analyses. Categorical variables were presented as means \pm standard deviations, and continuous variables were presented as frequencies or proportions with percentages. Missing values were handled using the Markov chain Monte Carlo single-imputation method.

The primary endpoint for the risk prediction model was operative mortality that occurred within 30 days of surgery or during the same hospitalization period. To estimate the significant risk factors for operative mortality, multivariable logistic regression analyses were performed. Of all data fields registered in the KHVSR, the authors a priori reviewed and selected 25 potentially relevant risk variables listed in Table 1. The number of operated valves (Table 2) and concomitant procedures (Table 3 ) were also primarily fitted in the univariable models.

The multivariable models were validated with a bootstrap method that generated 1,000 random samples $(\mathrm{n}=4,742)$ with replacement. A stepwise backward elimination process was performed in every bootstrap sample to evaluate the reliability of risk variables to be retained in the final risk prediction models, and risk variables selected $\geq 400$ times in the 1,000 bootstrap models were then retained in the final risk prediction model [11]. Although the extent of the procedure, which was quantified as the number of operated valves (Table 2), was not retained in the final model, we assumed that the extent of the procedure may have significant clinical implications. Accordingly, we developed 2 risk prediction models depending on the fitting of the extent of the procedure. All reported p-values were 2 -tailed, and $\mathrm{p}$-values $<0.05$ were considered to indicate statistical significance.

The risk prediction models were developed using a scoring system based on penalized maximum likelihood estimates of each risk variable. The multivariable logistic regression $\beta$ coefficient of each risk variable was transformed into an integer risk score by rounding the quotient of the $\beta$ coefficient divided by a single constant. The constant was the $\beta$ coefficient for a 20 -year increment in age, thereby allowing the risk score for a 20 -year increment in age to be 1 
Table 1. Baseline characteristics of the study population

\begin{tabular}{|c|c|c|}
\hline Characteristic & Value & No. of missing data \\
\hline Age $(y r)$ & $62.4 \pm 13.2$ & 2 \\
\hline$\geq 80$ & $282(5.9)$ & \\
\hline$\geq 60$ and $<80$ & $2,727(57.5)$ & \\
\hline$<60$ & $1,731(36.5)$ & \\
\hline Female & $2,242(47.3)$ & 0 \\
\hline Body mass index $\left(\mathrm{kg} / \mathrm{m}^{2}\right)$ & $23.9 \pm 3.6$ & 2 \\
\hline Smoking history & & 8 \\
\hline Never smoker & $3,448(72.7)$ & \\
\hline Current smoker & $392(8.3)$ & \\
\hline Previous smoker & $894(18.9)$ & \\
\hline Emergency or urgency & $366(7.7)$ & 0 \\
\hline New York Heart Association class 3 or 4 & $1,235(26.0)$ & 0 \\
\hline Preoperative heart rhythm & & 0 \\
\hline Normal sinus rhythm & $3,011(63.5)$ & \\
\hline Atrial fibrillation & $1,594(33.6)$ & \\
\hline Others & $137(2.9)$ & \\
\hline Hypertension & $2,165(45.7)$ & 0 \\
\hline Diabetes & $896(18.9)$ & 0 \\
\hline Dyslipidemia & $1,244(26.2)$ & 0 \\
\hline Chronic kidney disease & $364(7.7)$ & 0 \\
\hline Dialysis & $132(2.8)$ & 0 \\
\hline Chronic lung disease & $315(6.6)$ & 0 \\
\hline Peripheral arterial occlusive disease & $264(5.6)$ & 0 \\
\hline History of stroke & $364(7.7)$ & 0 \\
\hline Infective endocarditis & $347(7.3)$ & 0 \\
\hline Previous cardiac surgery & $812(17.1)$ & 0 \\
\hline History of myocardial infarction & $140(3.0)$ & 3 \\
\hline Hemoglobin (g/dL) & $12.5 \pm 2.0$ & 2 \\
\hline$\geq 13$ & $2,071(43.7)$ & \\
\hline$<13$ & $2,669(56.3)$ & \\
\hline Estimated glomerular filtration rate $\left(\mathrm{mL} / \mathrm{min} / 1.73 \mathrm{~m}^{2}\right)$ & $75.7 \pm 25.9$ & 3 \\
\hline$\geq 60$ & $3,638(76.8)$ & \\
\hline$\geq 30$ and $<60$ & $871(18.4)$ & \\
\hline$<30$ & $230(4.6)$ & \\
\hline \multicolumn{3}{|l|}{ Echocardiographic profile } \\
\hline LV ejection fraction (\%) & $58.8 \pm 10.8$ & 34 \\
\hline$\geq 55$ & $3,512(74.6)$ & \\
\hline$\geq 30$ and $<55$ & $1,104(23.5)$ & \\
\hline$<30$ & $92(2.0)$ & \\
\hline LV end-systolic dimension (mm) & $35.6 \pm 9.1$ & 56 \\
\hline LV end-diastolic dimension (mm) & $53.9 \pm 9.4$ & 46 \\
\hline Systolic pulmonary artery pressure (mm Hg) & $37.8 \pm 16.1$ & 402 \\
\hline Aortic valve disease ${ }^{a)}$ & & 17 \\
\hline Severe aortic stenosis & $1,728(36.6)$ & \\
\hline Significant aortic regurgitation ( $\geq$ moderate) & $606(12.8)$ & \\
\hline Mitral valve disease ${ }^{a}$ & & 17 \\
\hline Severe mitral stenosis & $590(12.5)$ & \\
\hline Significant mitral regurgitation ( $\geq$ moderate) & $1,288(27.3)$ & \\
\hline Tricuspid regurgitation & & 38 \\
\hline None-to-trivial & $2,636(56.0)$ & \\
\hline Mild & $1,097(23.3)$ & \\
\hline Moderate & $409(8.7)$ & \\
\hline Severe & $562(11.9)$ & \\
\hline
\end{tabular}

Values are presented as mean \pm standard deviation or number (\%), unless otherwise stated.

$\mathrm{LV}$, left ventricular.

a) Included only the patients with native valve disease and excluded the patients with valve disease from infectious etiology. 
Table 2. Operative profiles and sample sizes

\begin{tabular}{|c|c|}
\hline Operation & No. of cases \\
\hline Isolated valve surgery & 3,471 \\
\hline Aortic valve replacement & 1,845 \\
\hline Mitral valve replacement & 462 \\
\hline Mitral valve repair & 611 \\
\hline Tricuspid valve replacement & 82 \\
\hline Tricuspid valve repair & 187 \\
\hline Pulmonary valve surgery & 14 \\
\hline Aortic root reimplantation (David) & 52 \\
\hline Aortic root replacement (Bentall) & 218 \\
\hline Combined valve surgery (double valve) & 1,075 \\
\hline $\begin{array}{l}\text { Aortic valve replacement+mitral valve } \\
\text { replacement }\end{array}$ & 218 \\
\hline Aortic valve replacement+mitral valve repair & 50 \\
\hline $\begin{array}{l}\text { Aortic valve replacement+tricuspid valve } \\
\text { repair }\end{array}$ & 94 \\
\hline $\begin{array}{l}\text { Aortic valve replacement+tricuspid valve } \\
\text { replacement }\end{array}$ & 15 \\
\hline $\begin{array}{l}\text { Aortic valve replacement+pulmonary valve } \\
\text { surgery }\end{array}$ & 1 \\
\hline Mitral valve replacement+aortic root surgery ${ }^{\mathrm{a})}$ & 3 \\
\hline $\begin{array}{l}\text { Mitral valve replacement+tricuspid valve } \\
\text { repair }\end{array}$ & 434 \\
\hline $\begin{array}{l}\text { Mitral valve replacement+tricuspid valve } \\
\text { replacement }\end{array}$ & 21 \\
\hline Bentall operation+mitral valve repair & 6 \\
\hline Bentall operation+tricuspid valve repair & 5 \\
\hline $\begin{array}{l}\text { Bentall operation+tricuspid valve } \\
\text { replacement }\end{array}$ & 1 \\
\hline Bentall operation+pulmonary valve surgery & 2 \\
\hline David operation+mitral valve repair & 6 \\
\hline David operation+tricuspid valve repair & 1 \\
\hline Mitral valve repair+tricuspid valve repair & 209 \\
\hline $\begin{array}{l}\text { Mitral valve repair+tricuspid valve } \\
\text { replacement }\end{array}$ & 4 \\
\hline $\begin{array}{l}\text { Tricuspid valve repair+pulmonary valve } \\
\text { surgery }\end{array}$ & 4 \\
\hline $\begin{array}{l}\text { Tricuspid valve replacement+pulmonary } \\
\text { valve surgery }\end{array}$ & 1 \\
\hline Combined valve surgery (triple valve) & 196 \\
\hline $\begin{array}{l}\text { Aortic valve+mitral valve+tricuspid valve } \\
\text { surgery }\end{array}$ & 188 \\
\hline $\begin{array}{l}\text { Aortic valve+mitral valve+pulmonary valve } \\
\text { surgery }\end{array}$ & 1 \\
\hline Bentall+mitral valve+tricuspid valve surgery & 4 \\
\hline $\begin{array}{l}\text { Bentall+tricuspid valve+pulmonary valve } \\
\text { surgery }\end{array}$ & 3 \\
\hline
\end{tabular}

a) Included both aortic root reimplantation (David operation) and aortic root replacement (Bentall operation).

point. Therefore, the total risk score for each patient was calculated as the sum of the risk score for the selected variables.
Table 3. Concomitant procedures

\begin{tabular}{lc}
\hline \multicolumn{1}{c}{ Concomitant procedures } & No. of cases (\%) \\
\hline Coronary artery bypass grafting & $346(7.3)$ \\
Atrial fibrillation surgery & $976(20.6)$ \\
Aorta replacement & $493(10.4)$ \\
Cardiac tumor resection & $6(0.1)$ \\
$\begin{array}{l}\text { Congenital correction (atrial septal defect, } \\
\text { ventricular septal defect) }\end{array}$ & $126(2.7)$ \\
\hline
\end{tabular}

The discrimination and calibration abilities of the risk prediction models were assessed with the c-statistic and Hosmer-Lemeshow goodness-of-fit test. For internal validation, 1,000 random bootstrap samples with replacement $(\mathrm{n}=4,742)$ were drawn to obtain an optimism-corrected c-statistic [12]. Additionally, the performance of the risk prediction models was also validated on external cohorts composed of patients who underwent surgery between January 2019 and June 2019 and were then registered in the KHVSR until November 30, 2019. In the development and validation set, calibration was also assessed by plotting actual versus predicted mortality rates across deciles of predicted risk [13].

\section{Results}

\section{Baseline characteristics and operative profiles}

A total of 4,766 patients who underwent heart valve surgery at the 9 participating institutions were registered in the KHVSR during the study period. Of them, 24 patients who underwent cardiac surgery other than valve replacement/repair surgery were excluded. Consequently, 4,742 patients were enrolled in this study.

Table 1 summarizes the baseline characteristics of the study cohort. The mean age of the patients was $62.4 \pm 13.2$ years, and 2,242 (47.3\%) were women. Non-elective surgery accounted for $7.7 \%$ of the patients $(\mathrm{n}=366)$, and $812 \mathrm{pa}-$ tients (17.1\%) had a history of previous cardiac surgery. Isolated valve surgery was performed in 3,471 patients (73.2\%), whereas the remaining 1,271 (26.8\%) underwent combined valve surgery (Table 2, Supplementary Fig. 1). Concomitant procedures were performed in 1,789 patients (37.7\%), and 160 (3.4\%) received $\geq 2$ types of concomitant procedures (Table 3). Atrial fibrillation (AF) surgery was most frequently performed concomitantly in these patients $(\mathrm{n}=976,20.6 \%)$, followed by aorta replacement $(\mathrm{n}=493$, $10.4 \%)$ and CABG ( $\mathrm{n}=346,7.3 \%)$. 


\section{Operative outcomes}

Operative mortality occurred in 142 patients (3.0\%). Of these, 87 and 55 patients underwent isolated and combined valve surgery, respectively (Supplementary Table 1). The operative mortality rate according to the number of operated valves was $2.5 \%$ for an isolated valve, $4.1 \%$ for a double valve, and $5.6 \%$ for a triple valve. Among patients who underwent concomitant CABG $(n=346)$ and AF surgery $(\mathrm{n}=976)$, operative mortality occurred in 24 patients $(6.9 \%)$ and 26 patients $(2.7 \%)$, respectively (Supplementary Table 2).

\section{Development of risk prediction models for operative mortality}

Twenty risk variables were identified as candidate variables in the univariable logistic regression analyses (Supplementary Table 3). In the 1,000 bootstrap random samples, 13 risk variables emerged as significant predictors for operative mortality with a frequency of $\geq 400$ in the multivariable analyses (model 1 in Table 4): age, New York Heart Association class 3 or 4, elective versus non-elective surgery, body mass index (BMI), diabetes, infective endocarditis, estimated glomerular filtration rate (eGFR), history of stroke, previous cardiac surgery, anemia (hemoglobin $<13 \mathrm{~g} / \mathrm{dL}$ ) [14], concomitant CABG, left ventricular (LV) dysfunction (LV ejection fraction), and significant tricuspid regurgitation. In model 2, the number of operated valves was also incorporated as a risk variable (Table 4). Regarding statistical performance, models 1 and 2 achieved adequate discrimination, with c-statistics of 0.805 and 0.804, respectively; calibration ability was also acceptable, with Hosmer-Lemeshow p-values of 0.630 and 0.494 , respectively.

Continuous variables were categorized into risk groups based on clinical implications or with reference to previous studies [7,14-16]. The $\beta$ coefficient for a 20 -year increment in age was 0.446 in model 1 and 0.440 in model 2 . The $\beta$ coefficients of risk variables in each risk prediction model were converted to risk scores (Table 5). Of note, BMI values $\geq 25 \mathrm{~kg} / \mathrm{m}^{2}$ were found to have a negative predictive value for operative mortality in model 1 ( $\beta$ coefficient $=-0.375$ ) and model 2 ( $\beta$ coefficient $=-0.360$ ). Thus, the sum of the risk scores ranged from -1 to 15 in model 1 , and from -1 to 16 in model 2. The risk scores of the study cohort ranged from -1 to 11 in model 1 , and from -1 to 12 in model 2 (Fig. 1). The incidence of postoperative mortality tended to be higher in patients with higher risk scores in both model 1 (Fig. 1A) and model 2 (Fig. 1B). The mortality rate was

Table 4. Risk variables for operative mortality in the multivariable logistic regression models

\begin{tabular}{|c|c|c|c|c|}
\hline \multirow{2}{*}{ Risk factors } & \multicolumn{2}{|c|}{ Multivariable model 1} & \multicolumn{2}{|c|}{ Multivariable model 2} \\
\hline & OR $(95 \% \mathrm{Cl})$ & p-value & OR $(95 \% \mathrm{Cl})$ & p-value \\
\hline Age & $1.02(1.01-1.04)$ & 0.005 & $1.02(1.01-1.04)$ & 0.005 \\
\hline New York Heart Association class 3 or 4 & $1.41(1.00-1.99)$ & 0.0501 & $1.40(0.995-1.96)$ & 0.053 \\
\hline Elective vs. emergency/urgency & $2.07(1.37-3.14)$ & $<0.001$ & $2.05(1.36-3.08)$ & 0.001 \\
\hline Body mass index & $0.93(0.88-0.98)$ & 0.004 & $0.93(0.88-0.98)$ & 0.005 \\
\hline Diabetes & $1.39(0.96-2.01)$ & 0.081 & $1.39(0.96-1.99)$ & 0.078 \\
\hline Infective endocarditis & $1.58(0.98-2.53)$ & 0.056 & $1.54(0.98-2.43)$ & 0.064 \\
\hline \multicolumn{5}{|c|}{ Estimated glomerular filtration rate $\left(\mathrm{mL} / \mathrm{min} / 1.73 \mathrm{~m}^{2}\right)$} \\
\hline$\geq 60$ vs. $30-60$ & $1.52(1.03-2.25)$ & 0.034 & $1.51(1.03-2.21)$ & 0.034 \\
\hline$\geq 60$ vs. $<30$ & $2.67(1.68-4.23)$ & $<0.001$ & $2.59(1.65-4.06)$ & $<0.001$ \\
\hline History of stroke & $1.60(1.02-2.50)$ & 0.041 & $1.55(0.998-2.40)$ & 0.051 \\
\hline Previous cardiac surgery & $1.86(1.29-2.68)$ & 0.001 & $1.82(1.27-2.61)$ & 0.001 \\
\hline Concomitant coronary artery bypass grafting & $1.94(1.26-3.07)$ & 0.005 & $1.90(1.21-2.98)$ & 0.005 \\
\hline Hemoglobin $(\mathrm{mg} / \mathrm{dL})$ & $0.86(0.78-0.94)$ & 0.001 & $0.85(0.78-0.94)$ & 0.001 \\
\hline \multicolumn{5}{|l|}{ Echocardiographic profile } \\
\hline Left ventricular ejection fraction (\%) & $0.99(0.97-0.99)$ & 0.043 & $0.99(0.97-1.00)$ & 0.044 \\
\hline \multicolumn{5}{|l|}{ Tricuspid regurgitation } \\
\hline$\leq$ Mild vs. $\geq$ moderate & $1.51(1.05-2.16)$ & 0.025 & $1.39(0.95-2.04)$ & 0.095 \\
\hline \multicolumn{5}{|l|}{ No. of operated valves } \\
\hline Isolated vs. combined (double) & & & $1.15(0.78-1.69)$ & 0.490 \\
\hline Isolated vs. combined (triple) & & & $1.29(0.73-2.27)$ & 0.383 \\
\hline
\end{tabular}

$\mathrm{OR}$, odds ratio; $\mathrm{Cl}$, confidence interval. 
Table 5. $\beta$ coefficients and risk scores for operative mortality

\begin{tabular}{|c|c|c|c|c|}
\hline \multirow{2}{*}{ Risk factors } & \multicolumn{2}{|c|}{ Model 1} & \multicolumn{2}{|c|}{ Model 2} \\
\hline & $\beta$ coefficient & Risk score & $\beta$ coefficient & Risk score \\
\hline \multicolumn{5}{|l|}{ Age $(y r)$} \\
\hline$\geq 60$ and $<70$ & 0.368 & 1 & 0.363 & 1 \\
\hline$\geq 70$ and $<80$ & 0.579 & 1 & 0.572 & 1 \\
\hline$\geq 80$ & 0.757 & 2 & 0.747 & 2 \\
\hline \multicolumn{5}{|l|}{ New York Heart Association class } \\
\hline Class 1 or 2 vs. 3 or 4 & 0.344 & 1 & 0.334 & 1 \\
\hline Elective vs. emergency/urgency & 0.727 & 2 & 0.717 & 2 \\
\hline \multicolumn{5}{|l|}{ Body mass index $\left(\mathrm{kg} / \mathrm{m}^{2}\right)$} \\
\hline$<20$ & 0.319 & 1 & 0.306 & 1 \\
\hline$\geq 25$ & -0.375 & -1 & -0.360 & -1 \\
\hline Diabetes & 0.329 & 1 & 0.326 & 1 \\
\hline Infective endocarditis & 0.458 & 1 & 0.432 & 1 \\
\hline \multicolumn{5}{|c|}{ Estimated glomerular filtration rate $\left(\mathrm{mL} / \mathrm{min} / 1.73 \mathrm{~m}^{2}\right)$} \\
\hline$<30$ & 0.981 & 2 & 0.951 & 2 \\
\hline$\geq 30$ and $<60$ & 0.422 & 1 & 0.413 & 1 \\
\hline History of stroke & 0.468 & 1 & 0.437 & 1 \\
\hline \multicolumn{5}{|l|}{ Hemoglobin (mg/dL) } \\
\hline$<13$ vs. $\geq 13$ & 0.500 & 1 & 0.510 & 1 \\
\hline \multicolumn{5}{|l|}{ Left ventricular ejection fraction (\%) } \\
\hline$<30$ & 0.574 & 1 & 0.569 & 1 \\
\hline$\geq 30$ and $<55$ & 0.258 & 1 & 0.255 & 1 \\
\hline \multicolumn{5}{|l|}{ Tricuspid regurgitation } \\
\hline$\leq$ Mild vs. $\geq$ moderate & 0.410 & 1 & 0.327 & 1 \\
\hline Previous cardiac surgery & 0.618 & 1 & 0.598 & 1 \\
\hline Concomitant coronary artery bypass grafting & 0.663 & 1 & 0.640 & 1 \\
\hline \multicolumn{5}{|l|}{ No. of operated valves } \\
\hline Isolated vs. double valve & NA & NA & 0.137 & 0 \\
\hline Isolated vs. triple valve & NA & NA & 0.252 & 1 \\
\hline Total score & & 15 & & 16 \\
\hline
\end{tabular}

NA, not applicable.

lower in patients with scores of -1 to $4(1.2 \%)$ than the average rate $(3.0 \%)$ (Supplementary Table 4). In the subgroup of patients with a risk score $\geq 5$, the mortality rate was found to be significantly increased in patients with a score $\geq 7$.

Table 6 demonstrates the predicted probability rates for operative mortality as a function of the risk score. Based on the estimated total risk scores, the predicted risk of mortality ranged from $0.3 \%$ to $80.6 \%$ in model 1 , and from $0.3 \%$ to $85.5 \%$ in model 2 .

\section{Validation of risk prediction models}

Internal bootstrapping validation on 1,000 samples demonstrated an optimism-corrected c-statistic of 0.792 (95\% confidence interval [CI], 0.755-0.829) in model 1, and 0.789 (95\% CI, 0.753-0.826) in model 2, thereby indicating that the performance of the risk prediction model was good. These risk prediction models were also externally validated on 639 patients registered in the KHVSR who underwent surgery from January 2019 to June 2019. The c-statistic was 0.845 (95\% CI, 0.719-0.972) for model 1 and 0.842 (95\% CI, 0.715-0.969) for model 2. The calibration abilities assessed by the Hosmer-Lemeshow goodness-of-fit test were also acceptable in model $1(\mathrm{p}=0.637)$ and model 2 $(\mathrm{p}=0.675)$. Calibration graphs also demonstrated acceptable calibrations for operative mortality in the development (Fig. 2) and validation sets (Fig. 3).

\section{Discussion}

The major findings of this study relate to the development of risk prediction models for operative mortality following heart valve surgery, using a cohort that constituted 
A
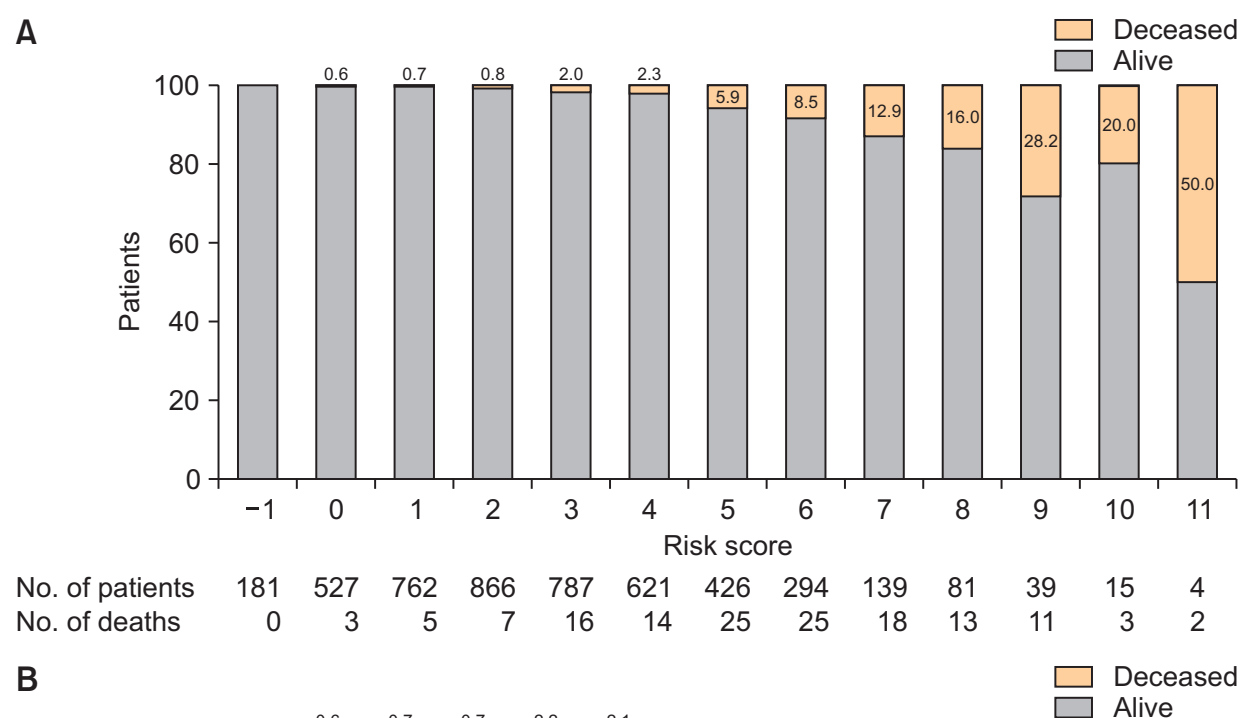

B

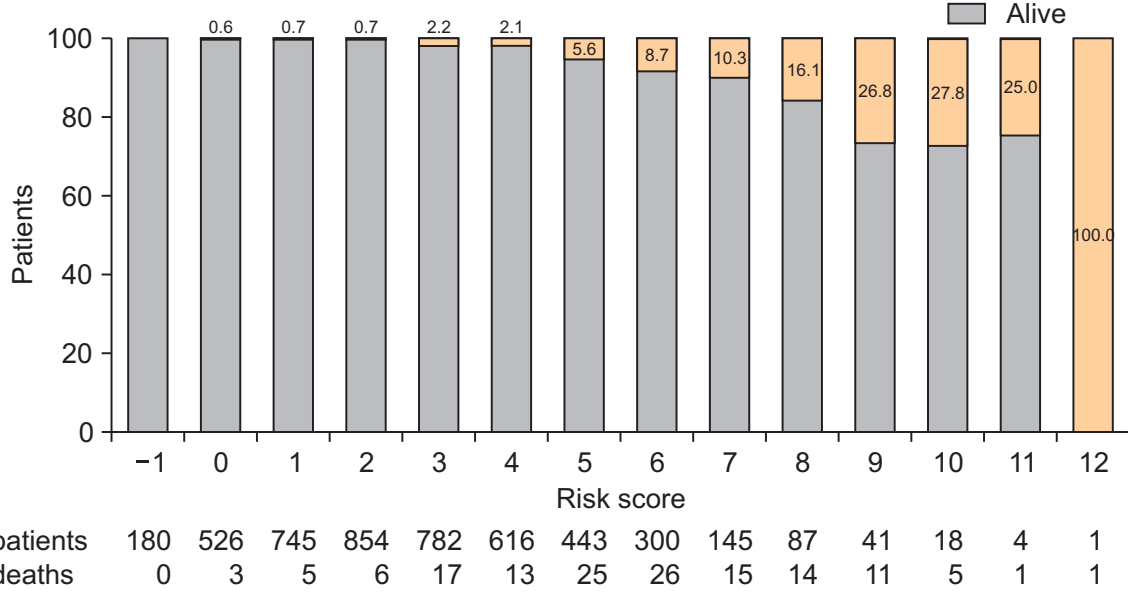

Fig. 1. Risk scores and the rate of operative mortality in model 1 (A) $\begin{array}{lllllllllllllll}\text { No. of patients } & 180 & 526 & 745 & 854 & 782 & 616 & 443 & 300 & 145 & 87 & 41 & 18 & 4 & 1\end{array}$ and model 2 (B) after heart valve surgery.

a majority of the recent clinical outcomes of patients in Korea. The KHVSR was established in 2017 by the Korean Society of Thoracic and Cardiovascular Surgery as a nationwide collaborative effort to improve the quality of heart valve surgery and to enhance research activities. By generating a risk prediction model from the KHVSR database, this study presents an up-to-date multi-institutional analysis of operative mortality after heart valve surgery across medium- to high-volume hospitals in Korea. The risk prediction model was generated based on a readily calculable scoring system and was shown to perform well in a contemporary heart valve surgery cohort in Korea. This study, to our knowledge, represents the largest and most current analysis of nationwide operative outcomes, particularly dedicated to the wide spectrum of heart valve surgery with or without concomitant procedures. Therefore, we speculated that these risk prediction models may support cardiac surgeons and healthcare providers in obtaining more accurate assessments of operative mortality, as well as in counseling patients and families who are considering heart valve surgery in Korea.

The US- and Europe-derived risk prediction models have been most commonly used to assess the risk of cardiac surgery in Korea [7,8]. However, the performance of these risk prediction models has been frequently challenged for a specific regional population, subgroups of a particular disease [17], or specific types of cardiac procedure [18,19]. The European System for Cardiac Operative Risk Evaluation (EuroSCORE) II model was generated to assess the mortality risk of all types of cardiac procedures [7]. However, it has been suggested that the EuroSCORE II risk prediction model may not perform well for patients undergoing heart valve surgery with or without combined procedures [20], or those in endemic areas of rheumatic heart disease [21]. The Society of Thoracic Surgeons (STS) risk prediction models are procedure-specific and only evaluate single-valve surgery, such as aortic/mitral valve replacement or mitral valve repair [8]; therefore, they are not applicable 
Table 6. Predicted risk of operative mortality by the risk score in models 1 and 2

\begin{tabular}{rcc}
\hline \multirow{2}{*}{ Risk score } & Predicted risk of operative mortality $(\%)$ \\
\cline { 2 - 3 } & Model 1 & Model 2 \\
\hline-1 & 0.3 & 0.3 \\
0 & 0.5 & 0.5 \\
1 & 0.8 & 0.8 \\
2 & 1.2 & 1.2 \\
3 & 1.9 & 1.9 \\
4 & 3.0 & 2.9 \\
5 & 4.6 & 4.4 \\
6 & 6.9 & 6.7 \\
7 & 10.5 & 10.1 \\
8 & 15.4 & 14.8 \\
9 & 22.2 & 21.3 \\
10 & 30.8 & 29.6 \\
11 & 41.0 & 39.5 \\
12 & 52.1 & 50.3 \\
13 & 62.9 & 61.2 \\
14 & 72.6 & 71.0 \\
15 & 80.6 & 79.2 \\
16 & NA & 85.5 \\
\hline
\end{tabular}

NA, not applicable.

to the $26.8 \%$ of patients who underwent multi-valve surgery $(n=1,271)$ in our cohort.

Compared to other developed countries, Korea has unique demographic features: specifically, the aging population is growing faster than that in any other region in the world $[5,22]$, and there is still a high prevalence of rheumatic heart disease, which is known to be generally prevalent in developing countries [23]. Moreover, coronary bypass surgery is less frequently performed than in other countries, as demonstrated by the reported ratio of percutaneous coronary interventions to CABG of 19.12 in Korea, compared to the average ratio of 5.92 in the Organization for Economic Cooperation and Development member countries $[6,24]$. Accordingly, heart valve surgery has become the most common cardiac procedure in Korea, and the necessity of developing a risk prediction model specific to Korea following heart valve surgery has been pointed out.

Using the KHVSR database, we identified 13 readily available risk factors for operative mortality that were incorporated into the risk prediction models. Of these, advanced age ( $\geq 80$ years), an emergent or urgent operation, and severe renal dysfunction with an eGFR $<30 \mathrm{~mL}$ / $\mathrm{min} / 1.73 \mathrm{~m}^{2}$ were found to be most strongly associated with an increased risk of operative mortality, which was scored as 2 points in our risk prediction models. These re- sults imply that timely surgery may reduce the risk of operative mortality before patients become too old or suffer from circulatory collapse due to a delayed surgical referral.

Renal dysfunction was also proven to be related to an increased risk of operative mortality after heart valve surgery in our cohort. This may be attributed to the higher prevalence of comorbidities leading to increased operative complications and higher calcific burdens in the valvular leaflets and annular structures, making surgical procedures more technically challenging [25]. It is also noteworthy that a consistent trend was found in our study for operative mortality and morbidity to be lower in obese patients after cardiac surgery, which appeared to be paradoxical and was reflected in the risk prediction model (-1 for patients with a $\mathrm{BMI} \geq 25 \mathrm{~kg} / \mathrm{m}^{2}$ ) [15].

In designing the risk prediction model, we initially intended to evaluate the procedural burden on the risk of mortality by analyzing the extent of heart valve surgery (isolated versus combined or aortic root procedure) and the performance of concomitant procedures (Table 3). Although the mortality risk was numerically higher in patients with combined valve surgery (Supplementary Table 1), the extent of the procedure was not associated with an increased risk of mortality in the final multivariable risk analysis, and model 2 (incorporating the extent of the procedure) did not show better discrimination and calibration abilities than model 1 . As for concomitant procedures, the addition of the 2 most common procedures (AF surgery and aorta replacement), did not increase the risk of operative mortality, which is consistent with a recent study [26] and guidelines $[27,28]$. However, concomitant CABG was shown to be significantly associated with an increased risk of mortality during heart valve surgery, which agrees with the STS risk prediction models that evaluate combined valvular and coronary bypass surgery as separate procedural entities [8].

Our risk prediction models are limited by the small number of participating institutions $(n=9)$, which included mainly high- and medium-volume centers. As small-volume centers constitute most of the Korean institutions that perform open heart surgery, whether our risk prediction model can be applied to patients receiving cardiac surgery at such centers warrants further validation. It should also be noted that the number of patients in our study cohort was relatively small $(n=4,742)$ compared to the number of patients enrolled to generate other nation-specific risk prediction models $[9,10]$, as well as the US and European models $[7,8]$. According to annual reports from the Korea Heart Foundation (www.heart.or.kr), the nationwide vol- 

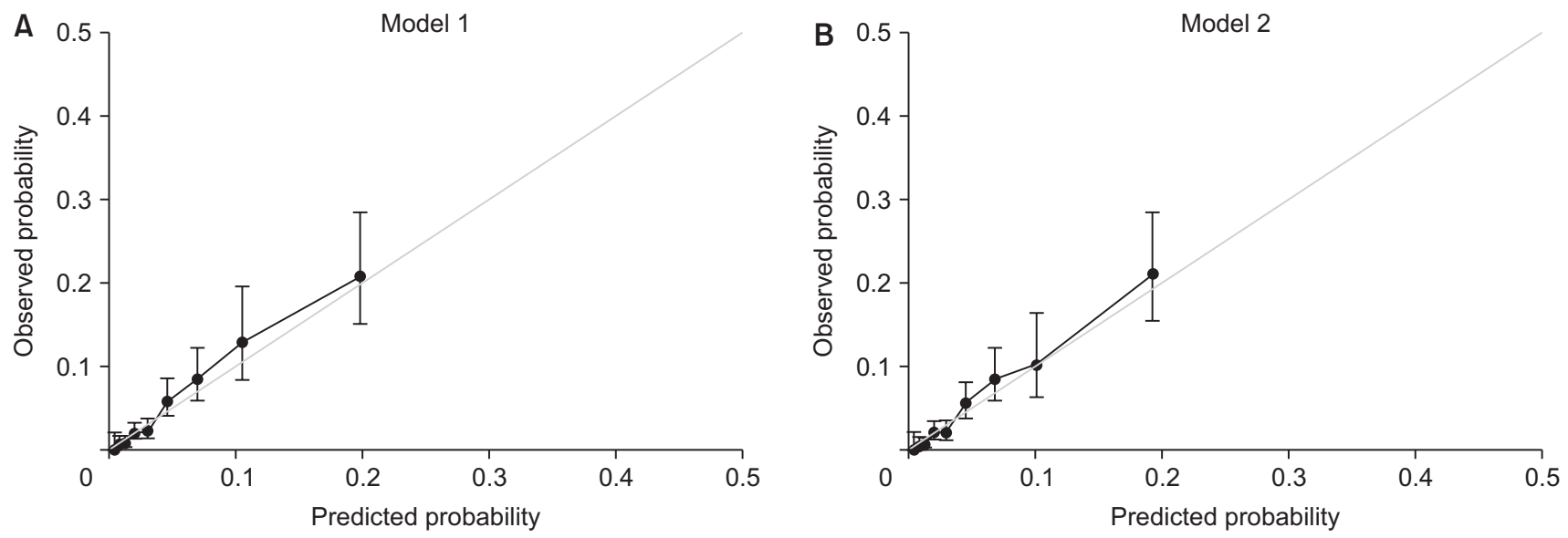

Fig. 2. (A, B) Calibration for operative mortality in the development sample.
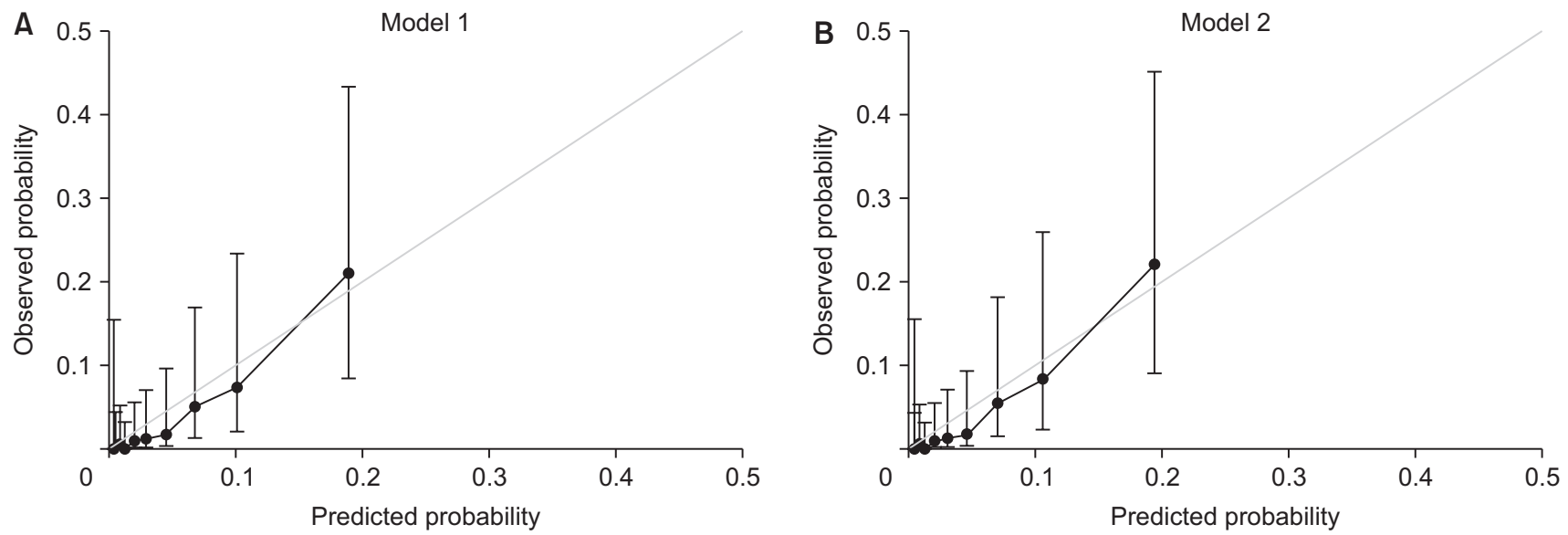

Fig. 3. (A, B) Calibration for operative mortality in the validation sample.

ume of heart valve surgery was 3,930 cases from 71 institutions in 2017 and 4,141 cases from 73 institutions in 2018, with a mortality rate of $3.9 \%$ and $3.2 \%$ in 2017 and 2018 , respectively [29]. Given these nationwide volumes, we estimate that approximately $59 \%$ of the patients undergoing heart valve surgery in Korea between 2017 and 2018 were incorporated into the risk prediction model, and mortality occurred in 144 patients (4.3\%) at the institutions that did not participate in the KHVSR, which is significantly higher than the rate at institutions that did participate in the $\mathrm{KH}$ VSR $(3.0 \%)(\mathrm{p}<0.001)$. Therefore, the risk prediction model in this study should be interpreted with caution because of selection bias, and future efforts to register a larger number of patients in the KHVSR across low- to high-volume centers are warranted to obtain a more adequately representative cohort of patients undergoing heart valve surgery in Korea. Thereby, we believe that the current risk prediction model will be more refined in the next version, with a larger national cohort of patients undergoing heart valve surgery using a more sophisticated KHVSR dataset to discriminate the risk of procedural extent between isolated and combined valve surgery and analyze the impact of currently unavailable risk variables such as critical status (e.g., preoperative extracorporeal membrane oxygenation) or frailty.

In conclusion, we developed a risk prediction model dedicated to heart valve surgery with a scoring system using preoperative patient data from the KHVSR. The operative mortality after heart valve surgery can be predicted well with this risk prediction model in a Korean cohort. Moreover, the results of the present analyses highlight the significance of collaborative nationwide efforts to collect patient data after cardiac surgery. This risk prediction model may also provide an important foundation for the identification of high-risk patients, thereby supporting cardiac surgeons and healthcare providers in providing optimal 
therapies to patients with valvular heart disease in Korea.

\section{Conflict of interest}

No potential conflict of interest relevant to this article was reported.

\section{Acknowledgments}

The authors are thankful to the following research coordinators and data managers for the efforts in collecting the KHVSR data: Young Ok Yoo, Jin Kyoung Kim, Hye Won Jo, Se Un Kim, and An You Jung (Asan Medical Center); Sang Eun Lee (Sejong General Hospital); Ji Hye Lee (Pusan National University Yangsan Hospital); Hyun Jung Han (Seoul National University Bundang Hospital); Hi Jae Lee (Severance Hospital); Ji Yeon Choi, Joomin Hwang, and Jiyoon Shin (Samsung Medical Center).

\section{Funding}

This work was supported by the National Evidence-based Healthcare Collaborating Agency (NA19-006), Republic of Korea

\section{ORCID}

Ho Jin Kim: https://orcid.org/0000-0002-0809-2240 Joon Bum Kim: https://orcid.org/0000-0001-5801-2395 Seon-Ok Kim: https://orcid.org/0000-0001-9010-5460 Sung-Cheol Yun: https://orcid.org/0000-0001-8503-109X Sak Lee: https://orcid.org/0000-0001-6130-2342 Cheong Lim: https://orcid.org/0000-0003-0913-7014 Jae Woong Choi: https://orcid.org/0000-0002-0921-756X Ho Young Hwang: https://orcid.org/0000-0002-8935-8118 Kyung Hwan Kim: https://orcid.org/0000-0002-2718-8758 Seung Hyun Lee: https://orcid.org/0000-0002-0311-6565 Jae Suk Yoo: https://orcid.org/0000-0002-7008-054X Kiick Sung: https://orcid.org/0000-0003-0768-9587 Hyung Gon Je: https://orcid.org/0000-0003-4713-2898 Soon Chang Hong: https://orcid.org/0000-0001-6415-8243 Yun Jung Kim: https://orcid.org/0000-0002-0449-1279 Sung-Hyun Kim: https://orcid.org/0000-0001-9587-674X Byung-Chul Chang: https://orcid.org/0000-0001-5005-8217

\section{Supplementary materials}

Supplementary materials can be found via https://doi. org/10.5090/kjtcs.20.102. Supplementary Table 1. Opera- tive mortality according to the number of operated valves. Supplementary Table 2. Operative mortality according to the performance of concomitant procedures. Supplementary Table 3. Risk variables for operative mortality in the univariable logistic regression models. Supplementary Table 4. Mortality rate according to the risk score groups. Supplementary Fig. 1. The rate of isolated and multi-valve surgery at each participating institution.

\section{References}

1. Statistics Korea. Cause of death in 2018 [Internet]. Daejeon: Statistics Korea; 2018 [cited 2020 Jul 13] Available from: http://kostat. go.kr/wnsearch/search.jsp.

2. Kim MS, Cho SJ, Park SJ, et al. Frequency and clinical associating factors of valvular heart disease in asymptomatic Korean adults. Sci Rep 2019;9:16741.

3. Mack MJ, Leon MB, Thourani VH, et al. Transcatheter aortic-valve replacement with a balloon-expandable valve in low-risk patients. $\mathrm{N}$ Engl J Med 2019;380:1695-705.

4. Popma JJ, Deeb GM, Yakubov SJ, et al. Transcatheter aortic-valve replacement with a self-expanding valve in low-risk patients. N Engl J Med 2019;380:1706-15.

5. Kim DH, Kang DH. Early surgery in valvular heart disease. Korean Circ J 2018;48:964-73.

6. Park SJ, Kim DJ, Kim JB, Park KH, Lee JW. Cardiothoracic surgery training in South Korea: challenges and new hopes. J Thorac Cardiovasc Surg 2019;159:205-14.

7. Nashef SA, Roques F, Sharples LD, et al. EuroSCORE II. Eur J Cardiothorac Surg 2012;41:734-44.

8. D'Agostino RS, Jacobs JP, Badhwar V, et al. The Society of Thoracic Surgeons Adult Cardiac Surgery Database: 2018 update on outcomes and quality. Ann Thorac Surg 2018;105:15-23.

9. Miyata H, Tomotaki A, Motomura N, Takamoto S. Operative mortality and complication risk model for all major cardiovascular operations in Japan. Ann Thorac Surg 2015;99:130-9.

10. Billah B, Reid CM, Shardey GC, Smith JA. A preoperative risk prediction model for 30-day mortality following cardiac surgery in an Australian cohort. Eur J Cardiothorac Surg 2010;37:1086-92.

11. Heinze G, Wallisch C, Dunkler D. Variable selection: a review and recommendations for the practicing statistician. Biom J 2018;60:43149.

12. Moons KG, Kengne AP, Woodward M, et al. Risk prediction models: I. development, internal validation, and assessing the incremental value of a new (bio)marker. Heart 2012;98:683-90.

13. Moons KG, Kengne AP, Grobbee DE, et al. Risk prediction models: II. external validation, model updating, and impact assessment. Heart 2012;98:691-8.

14. Loor G, Koch CG, Sabik JF 3rd, Li L, Blackstone EH. Implications 
and management of anemia in cardiac surgery: current state of knowledge. J Thorac Cardiovasc Surg 2012;144:538-46.

15. Mariscalco G, Wozniak MJ, Dawson AG, et al. Body mass index and mortality among adults undergoing cardiac surgery: a nationwide study with a systematic review and meta-analysis. Circulation 2017;135:850-63.

16. Eckardt KU, Berns JS, Rocco MV, Kasiske BL. Definition and classification of $C K D$ : the debate should be about patient prognosis: a position statement from KDOQI and KDIGO. Am J Kidney Dis 2009;53:915-20.

17. Patrat-Delon S, Rouxel A, Gacouin A, et al. EuroSCORE II underestimates mortality after cardiac surgery for infective endocarditis. Eur J Cardiothorac Surg 2016;49:944-51.

18. LaPar DJ, Likosky DS, Zhang M, et al. Development of a risk prediction model and clinical risk score for isolated tricuspid valve surgery. Ann Thorac Surg 2018;106:129-36.

19. Grant SW, Hickey GL, Dimarakis I, et al. How does EuroSCORE II perform in UK cardiac surgery: an analysis of 23740 patients from the Society for Cardiothoracic Surgery in Great Britain and Ireland National Database. Heart 2012;98:1568-72.

20. Singh N, Gimpel D, Parkinson G, et al. Assessment of the EuroSCORE II in a New Zealand tertiary centre. Heart Lung Circ 2019;28:1670-6.

21. Casalino R, Tarasoutchi F, Spina G, et al. EuroSCORE models in a cohort of patients with valvular heart disease and a high prevalence of rheumatic fever submitted to surgical procedures. PLoS One
2015; 10:e118357.

22. Kang DH, Park SJ, Lee SA, et al. Early surgery or conservative care for asymptomatic aortic stenosis. N Engl J Med 2020;382:111-9.

23. Kim WK, Kim HJ, Kim JB, et al. Clinical outcomes in 1731 patients undergoing mitral valve surgery for rheumatic valve disease. Heart 2018;104:841-8.

24. Lee H, Lee KS, Sim SB, Jeong HS, Ahn HM, Chee HK. Trends in percutaneous coronary intervention and coronary artery bypass surgery in Korea. Korean J Thorac Cardiovasc Surg 2016;49(Suppl 1):S60-7.

25. Marwick TH, Amann K, Bangalore S, et al. Chronic kidney disease and valvular heart disease: conclusions from a Kidney Disease: Improving Global Outcomes (KDIGO) Controversies Conference. Kidney Int 2019;96:836-49.

26. Idrees JJ, Roselli EE, Blackstone EH, et al. Risk of adding prophylactic aorta replacement to a cardiac operation. J Thorac Cardiovasc Surg 2020;159:1669-78.

27. Ad N, Damiano RJ Jr, Badhwar V, et al. Expert consensus guidelines: examining surgical ablation for atrial fibrillation. J Thorac Cardiovasc Surg 2017;153:1330-54.

28. Badhwar V, Rankin JS, Damiano RJ Jr, et al. The Society of Thoracic Surgeons 2017 clinical practice guidelines for the surgical treatment of atrial fibrillation. Ann Thorac Surg 2017;103:329-41.

29. The Korea Heart Foundation. Cardiac surgery annual report [Internet]. Seoul: The Korea Heart Foundation; 2018-2019 [cited 2020 Sep 6] Available from: https://www.heart.or.kr/Home/reference. 